\title{
PEMILIHAN DAGING KELAPA BERMUTU BERDASARKAN WARNA DAN TEKSTUR UNTUK PRODUKSI WINGKO BERKUALITAS MENGGUNAKAN METODE SUPPORT VECTOR MACHINE (SVM) DAN FUSI INFORMASI
}

\author{
Arwin Datumaya Wahyudi Sumari*1, Ahmad Alfian Bastami², Cahya Rahmad ${ }^{3}$ \\ ${ }^{1}$ Cognitive Artificial Intelligence Research Group (CAIRG), Teknik Elektro, Politeknik Negeri Malang \\ ${ }^{2,3}$ Program Studi Teknik Informatika, Jurusan Teknologi Informasi, Politeknik Negeri Malang \\ ${ }^{1}$ Lanud Abdulrachman Saleh, Komando Operasi II Angkatan Udara, Malang \\ E-mail: ${ }^{1}$ arwin.sumari@polinema.ac.id, ${ }^{2}$ ahmadalfianbastami@gmail.com, ${ }^{3}$ cahya.rahmad@polinema.ac.id \\ *Arwin Datumaya Wahyudi Sumari \\ *Penulis Korespondensi
}

(Naskah masuk: 23 November 2020, diterima untuk diterbitkan: 09 Juni 2021)

\begin{abstract}
Abstrak
Mutu daging kelapa adalah faktor utama yang menentukan kualitas produksi wingko baik yang berasal dari kelapa muda atau kelapa tua dari varietas Genjah. Dalam upaya menjaga kualitas produksi wingko kelapa, diperlukan teknik dalam memilih daging kelapa yang bermutu tinggi secara konsisten dengan bantuan teknologi. Dalam penelitian ini telah dibangun sebuah sistem pencitraan digital berbasis Kecerdasan Artifisial untuk pemilihan daging kelapa bermutu. Pemilihan tersebut didasarkan pada warna dan tekstur dengan memanfaatkan Support Vector Machine (SVM) sebagai pengklasifikasi, dan fusi informasi. Pengolahan citra digital menggunakan kombinasi metode Hue, Saturation, Value (HSV) dan metode Gray-Level Co-Occurrence Matrix (GLCM) sebagai pengekstraksi fitur warna dan fitur energi. Kedua macam fitur tersebut difusikan menjadi fitur tunggal guna mempercepat klasifikasi oleh SVM sebagai landasan pemilihan daging kelapa. Dengan menggunakan sistem ini, pemilihan daging kelapa bermutu berhasil mencapai akurasi sebesar 50\%. Dalam penelitian ini juga ditemukan bahwa ketidaktepatan pelabelan memberi dampak signifikan pada akurasi pemilihan daging kelapa.
\end{abstract}

Kata kunci: daging kelapa, fusi informasi, Kecerdasan Artifisial, pemilihan daging kelapa bermutu, pengolahan citra digital, Support Vector Machine

\section{SELECTION OF QUALITY COCONUT MEAT BASED ON COLOR AND TEXTURE FOR QUALITY WINGKO PRODUCTION USING SUPPORT VECTOR MACHINE (SVM) AND INFORMATION FUSION}

\begin{abstract}
The quality of coconut meat is a primary factor which determines the quality of wingko production whether that comes from young coconut or old one from Genjah variety. In the effort of maintaining the quality of coconut wingko production, a technique for selecting high quality of coconut meat in consistent way with the aid of technology is needed. In this research, an Artificial Intelligence-based digital imaging system for selecting quality coconut meat has been developed. The selection is based on color and texture by utilizing Support Vector Machine (SVM) as classifier and information fusion. The digital image processing uses the combination of Hue, Saturation, Value (HSV) and Gray-Level Co-Occurrence Matrix (GLCM) methods as color and energy feature extractors. Both features are fused to obtain single feature to accelerate SVM classification as the basis for selection the coconut meat. By using this system, the selection of quality coconut meat is successful to achieve the accuracy as much as 50\%. In this research it was also found that incorrectly labeling gives significant impact to the accuracy of coconut meat selection.
\end{abstract}

Keywords: Artificial Intelligence, coconut meat, digital image processing, information fusion, quality coconut meat selection, Support Vector Machine

\section{PENDAHULUAN}

Wingko babat adalah makanan tradisional khas Indonesia, yakni sejenis kue yang terbuat dari kelapa, ketan, dan gula (Sukrama, 2009). Dalam pembuatannya, jenis kelapa mempengaruhi tingkat kualitas produksi wingko. Pada umumnya wingko 
terbuat dari kelapa muda atau kelapa tua varietas genjah dimana bagian kelapa yang digunakan adalah bagian dagingnya. hijau. Kelapa jenis ini juga termasuk varietas unggul daerah/lokal (Warisno, 2003). Sebagai penganan tradisional Indonesia, wingko babat sangat disukai wisatawan baik dalam negeri maupun mancanegara. Selain itu wingko juga dapat menjadi buah tangan sehingga banyak anggota masyarakat yang mendirikan usaha produksi wingko babat dimana salah satunya adalah yakni UD. Putra Agung di Babat. Dalam upaya memenuhi permintaan pasar, perusahaan tersebut mampu memproduksi sebanyak 700 wingko dalam satu hari.

Kualitas wingko sangat ditentukan oleh kualitas daging kelapa yang digunakan sebagai bahan utama olahannya. Dengan adanya tuntutan produksi yang tinggi, maka kuantitas kelapa menjadi prioritas atau lebih diutamakan dibandingkan dengan kualitasnya di samping teknik pemilihan kelapa yang saat ini masih konvensional yakni menentukan kualitas daging kelapa dengan mengandalkan penglihatan para pekerja. Dampak dari kedua hal tersebut adalah kualitas daging kelapa yang diperoleh tidak semuanya sesuai dengan yang diharapkan sehingga wingko yang produksi menjadi kurang berkualitas dan merugikan dari sisi biaya produksi. Oleh karena itu diperlukan satu teknologi yang dapat membantu pengusaha wingko agar dapat memperoleh daging kelapa yang berkualitas.

Pada penelitian ini, dirancang dan diimplementasikan sebuah sistem pencitraan digital untuk pemilihan daging kelapa dengan teknologi Kecerdasan Artifisial menggunakan metode Support Vector Machine (SVM) yang dikombinasikan dengan fusi informasi. SVM digunakan sebagai pengklasifikasi daging kelapa untuk menentukan kualitasnya berdasarkan warna dan teksturnya. SVM merupakan pengklasifikasi yang banyak digunakan pada beragam permasalahan, seperti sebagai pengklasifikasi 12 motif Batik khas Banten (Wiryadinata dkk, 2019), klasifikasi kelapa berdasarkan warna dan tekstur yang dihasilkan dari pengolahan citra color moments dan teknik Gabor (Siddesha \& Niranjan, 2019), dan untuk identifikasi penyakit daun pada tanaman kubis dari fitur yang diperoleh melalui teknik Histogram Equalization (Ririd, Kurniawati, \& Yunhasnawa, 2018).

Untuk memudahkan memahami konsep, rancangan, dan implementasi sistem pencitraan digital untuk pemilihan daging kelapa menggunakan SVM dan fusi informasi, artikel ini diawali dengan Bagian 1 yang menyampaikan tentang latar belakang dan permasalahan yang sedang dihadapi oleh pengusaha wingko saat ini. Pada Bagian 2 akan disampaikan landasan dari teori-teori yang berkaitan dan dilanjutkan dengan Bagian 3 yang menyampaikan tentang metodologi penelitian. Implementasi dan pengujian sistem akan disampaikan pada Bagian 4, yang dilanjutkan dengan analisa dan pembahasan pada Bagian 5. Artikel ditutup dengan beberapa catatan penutup pada Bagian 6.

\section{METODE PENELITIAN}

\subsection{Data Penelitian}

Dalam penelitian ini digunakan data berupa citra daging kelapa sebanyak 200 buah dengan rincian 100 daging kelapa bermutu baik dan 100 daging kelapa bermutu kurang baik. Skema pelatihan dan pengujian yang dilakukan adalah 90:10. Untuk pelatihan SVM digunakan 90 daging kelapa bermutu baik dan 90 daging kelapa bermutu kurang baik, sedangkan untuk pengujian digunakan 10 daging kelapa bermutu baik dan 10 daging kelapa bermutu kurang baik. Contoh daging kelapa bermutu baik dan kurang baik diperlihatkan pada Gambar 1.

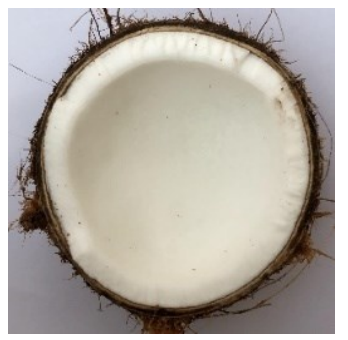

(a)

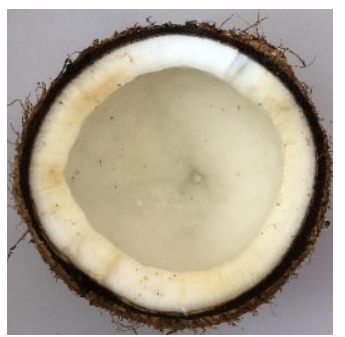

(b)
Gambar 1. Citra Daging Kelapa (a) Bermutu Baik, (b) Bermutu Kurang Baik

\subsection{Metode Pengambilan Data}

Data yang diperoleh adalah data primer berupa data hasil wawancara dengan pemilik usaha wingko Putra Agung dan data produksi, berupa data kualitas daging buah kelapa berdasarkan warna dan tekstur untuk membantu dalam mengklasifikasikan mutu daging kelapa menjadi dua kelas, yaitu kelas daging kelapa bermutu baik dan daging kelapa bermutu kurang baik. Untuk pengambilan citra daging kelapa yakni menggunakan kamera IPhone X 12 megapixel dengan jarak pengambilan gambar yakni $30 \mathrm{~cm}$ dan dengan latar belakang berwarna putih.

\subsection{Metode Pengolahan Data}

Secara keseluruhan, diagram blok sistem dapat dilihat pada Gambar 2. Alur sistem diawali dari masukan berupa citra daging kelapa yang kemudian dilakukan pengolahan awal (preprocessing) guna memperoleh fitur warna menggunakan HSV dan fitur tekstur menggunakan metode GLCM. Hasil dari ekstraksi fitur warna dan tekstur akan dicari nilai rata-ratanya masing-masing, dan kemudian dilakukan fusi fitur guna memperoleh satu fitur tunggal yang menjadi masukan bagi pengklasifikasi SVM.

Setelah melalui proses pelatihan dengan menggunakan 180 data latih, pengklasifikasi SVM akan diuji akurasi klasifikasinya menggunakan 20 data uji sebagaimana telah disampaikan pada Subbagian 3.1. Diagram alir proses klasifikasi mutu daging kelapa menggunakan metode SVM dan fusi informasi dapat dilihat pada Gambar 3. Pada gambar ini diperlihatkan informasi lengkap pada penggunaan setiap persamaan komputasi yang telah disampaikan 
pada Subbagian 2.2 hingga Subbagian 2.5, hingga memperoleh hasil klasifikasi berupa mutu daging kelapa yang baik atau kurang baik.

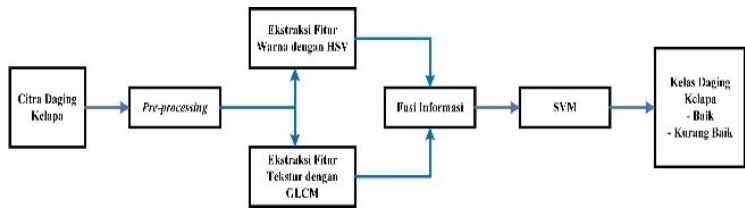

Gambar 2. Diagram blok sistem klasifikasi mutu daging kelapa.

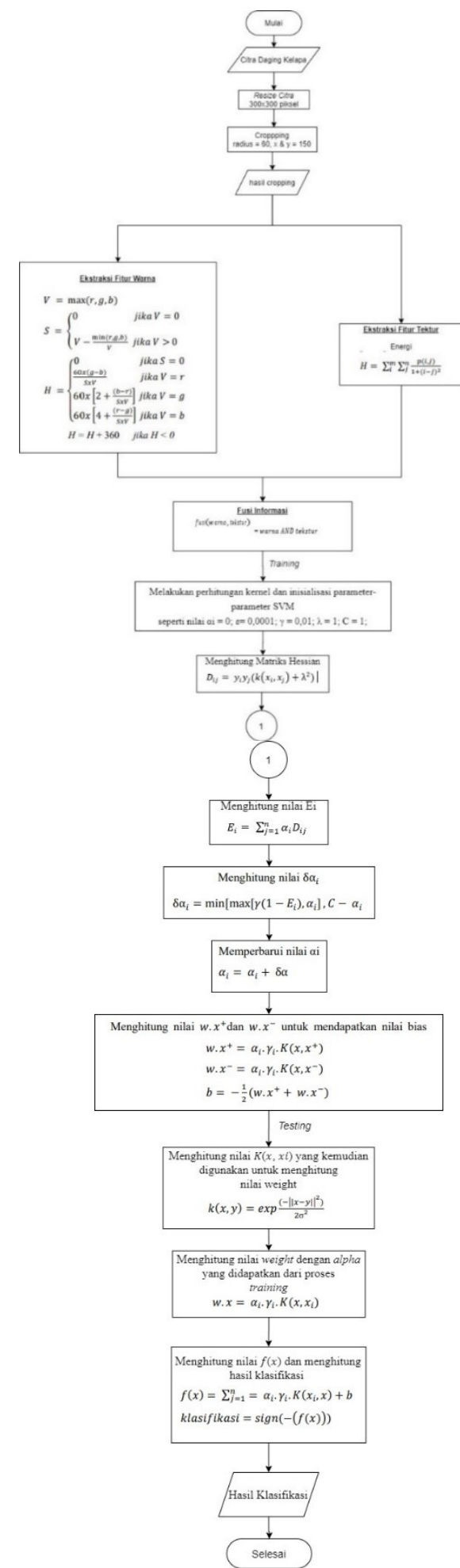

Gambar 3. Diagram alir klasifikasi mutu daging kelapa.

\section{LANDASAN TEORI}

\subsection{Citra Digital}

Citra adalah sebuah gambaran atau kemiripan dari sebuah obyek. Citra analog tidak dapat direpresentasikan dalam komputer sehingga tidak dapat diproses oleh komputer secara langsung. Agar dapat diproses oleh komputer, maka citra analog harus dikonversi menjadi citra digital, yakni citra yang dihasilkan dari peralatan digital (citra digital) (Pulung, Sutojo, \& Muljono, 2017). Secara teknis, citra (image) adalah angka (image is just a number). Sebuah citra direpresentasikan oleh banyak angka yang mewakili warna-warna yang ada padanya. Warna-warna tersebut merupakan kombinasi dari warna dasar citra yang disebut dengan Red, Green, Blue (RGB).

Citra adalah kumpulan warna yang dapat terlihat indah, memiliki pola, berbentuk abstrak dan lain sebagainya. Citra dapat berupa foto udara, penampang lintang (cross section) dari suatu benda, gambar wajah, hasil tomografi otak dan lain sebagainya (Widyardini, 2015). Tidak sulit bagi manusia untuk mengenali warna dan tekstur. Namun hal ini menjadi sebuah masalah tersendiri bagi mesin/ komputer. Maka cara untuk mengenalinya adalah dengan mengubahnya menjadi fitur-fitur yang bersesuaian menggunakan teknik-teknik dalam pengolahan citra digital seperti Hue, Saturation, Value (HSV) dan Gray-Level Co-Occurrence Matrix (GLCM).

\subsection{Hue, Saturation, Value (HSV)}

Citra adalah sebuah gambaran atau kemiripan dari sebuah obyek. Citra analog tidak dapat direpresentasikan dalam komputer sehingga tidak dapat diproses oleh komputer secara langsung. Agar dapat diproses oleh komputer, maka citra analog harus dikonversi menjadi citra digital, yakni citra yang dihasilkan dari peralatan digital (citra digital) (Pulung, Sutojo, \& Muljono, 2017). Secara teknis, citra (image) adalah angka (image is just a number). Sebuah citra direpresentasikan oleh banyak angka yang mewakili warna-warna yang ada padanya. Warna-warna tersebut merupakan kombinasi dari warna dasar citra yang disebut dengan Red, Green, Blue (RGB).

HSV adalah salah satu teknik untuk ekstraksi fitur warna. Model HSV menunjukkan ruang warna dalam bentuk tiga komponen utama yaitu hue, saturation, dan value (atau disebut brightness). Hue adalah sudut dari $0^{\circ}$ sampai $360^{\circ}$. Pada umumnya $0^{\circ}$ adalah merah, $60^{\circ}$ adalah kuning, $120^{\circ}$ adalah hijau, $180^{\circ}$ adalah cyan, $240^{\circ}$ adalah biru, dan $200^{\circ}$ adalah warna magenta. Hue menunjukkan jenis warna (seperti merah, biru, atau kuning) atau corak warna yaitu tempat warna tersebut ditemukan dalam spektrum warna. Merah, kuning, dan ungu (purple) adalah kata-kata hue. Saturasi (saturation) dari satu warna adalah ukuran seberapa besar kemurnian dari warna tersebut (Putra, 2010). Untuk memperoleh fitur 
warna dari sebuah citra, maka harus dilakukan konversi ke HSV menggunakan Persamaan (1), Persamaan (2), dan Persamaan (3).

$$
\begin{aligned}
& H=\tan \left[\frac{3(G-B)}{(R-G)+(R-B)}\right] \\
& S=1-\frac{\min (R, G, B)}{V} \\
& V=\frac{R+G+B}{3}
\end{aligned}
$$

Apabila $S=0$ maka $H$ tidak dapat ditentukan. Untuk itu diperlukan normalisasi RGB terlebih dahulu dengan menggunakan Persamaan (4), Persamaan (5), dan Persamaan (6).

$$
\begin{aligned}
& r=\frac{R}{255} \\
& g=\frac{G}{255} \\
& b=\frac{B}{255}
\end{aligned}
$$

Dengan memanfaatkan nilai $r, g$, dan $b$ yang telah ternormalisasi, maka konversi RGB ke HSV dilakukan dengan menggunakan Persamaan (7), Persamaan (8), dan Persamaan (9).

$$
\begin{aligned}
& V=\max (r, g, b) \\
& S=\left\{\begin{array}{cc}
0 & \text { jika } V=0 \\
V-\frac{\min (r, g, b)}{V} & \text { jika } V>0
\end{array}\right. \\
& S=\left\{\begin{array}{cc}
\frac{S * V}{2} \bmod 6 & \text { jika } V=r \\
60 *\left[2+\frac{(b-r)}{S * V}\right] & \text { jika } V=g \\
60 *\left[4+\frac{(r-g)}{S * V}\right] & \text { jika } V=b
\end{array}\right.
\end{aligned}
$$

dimana $H=H+360$, jika $H<0$.

\subsection{Gray Level Co-occurrence Matrix (GLCM)}

GLCM dapat dimanfaatkan sebagai pengekstraksi fitur diantaranya adalah fitur tekstur dari sebuah citra. Secara teknis, GLCM memiliki matriks persegi berukuran $N x N$, di mana $N$ mewakili tingkat keabuan sebuah citra. Sebuah elemen $p(i, j$, $d$, $\theta)$ GLCM dari sebuah citra mewakili frekuensi relatif, dimana $i$ merepresentasikan tingkat keabuan di lokasi $(x, y), j$ merupakan tingkat keabuan piksel tetangga dengan jarak $d$, dan orientasi $\theta$ dari lokasi $(x, y)$. Jarak $(d)$ yang digunakan umumnya adalah satu piksel dan orientasi sudut yang digunakan biasanya bernilai $0^{\circ}, 45^{\circ}, 90^{\circ}$, dan $135^{\circ}$. Formulasi matematika fitur tekstur dari GLCM terdiri atas Energi, Entropi, Homogen, Korelasi, dan Kontras.

Energi digunakan untuk mengukur konsentrasi pasangan intensitas, sedangkan Entropi digunakan untuk menunjukkan ketidakteraturan ukuran bentuk. Sebagai contoh adalah sebuah citra yang memiliki transisi derajat keabuan merata dan bernilai kecil namun memiliki nilai entropi yang besar. Fitur Homogen digunakan untuk menunjukkan kehomogenan variasi intensitas dalam citra, nilai Korelasi merepresentasikan derajat keabuan ketergantungan linier antara piksel pada posisi tertentu terhadap piksel lain, dan Kontras merepresentasikan variasi antar derajat keabuan satu daerah. Jika terletak jauh dari pusat diagonal utama, maka nilai kontras akan besar. Kelima fitur GLCM tersebut diperlihatkan pada Persamaan (10) sampai dengan Persamaan (14) (Kusuma, Pawening, \& Dijaya, 2017).

$$
\begin{aligned}
& H=\sum_{i}^{m} \sum_{j}^{n} \frac{p(i, j)}{i+(i-j)^{2}} \\
& E=\sum i \sum j p(i, j) \log (p(i, j)) \\
& E 1=\sum_{i}^{m} \sum_{j}^{n} p(i, j)^{2} \\
& C r=\frac{\sum_{i} \sum_{j}(i j) p(i, j)-\mu x \mu y}{\delta x \delta y} \\
& \operatorname{Var}=\sum_{i, j}(i-j)^{2} p(i, j)
\end{aligned}
$$

Notasi $p(i, j)$ melambangkan probabilitas, nilai mulai dari nol hingga satu, yaitu nilai elemen dalam matriks kejadian-bersama (co-occurrence), sedangkan $i$ dan $j$, melambangkan pasangan intensitas yang berdekatan (Saifudin \& Fadlil, 2015). Jarak direpresentasikan sebagai piksel sedangkan orientasi direpresentasikan dalam derajat. Orientasi terbentuk dari empat arah sudut dengan interval $45^{\circ}$, yaitu $0^{\circ}$, $45^{\circ}, 90^{\circ}$ dan $135^{\circ}$, dan jarak antar piksel ditentukan sebesar satu piksel (Surya, Fadlil, \& Yudhana, 2017). Keempat arah tersebut diperlihatkan pada Gambar 4. Setiap fitur dihitung dengan jarak satu piksel dalam empat arah, yaitu sudut $0^{\circ}, 45^{\circ}, 90^{\circ}$ dan $135^{\circ}$, kemudian nilai dari empat arah dirata-rata (Wahyudi \& Maulida, 2019). 


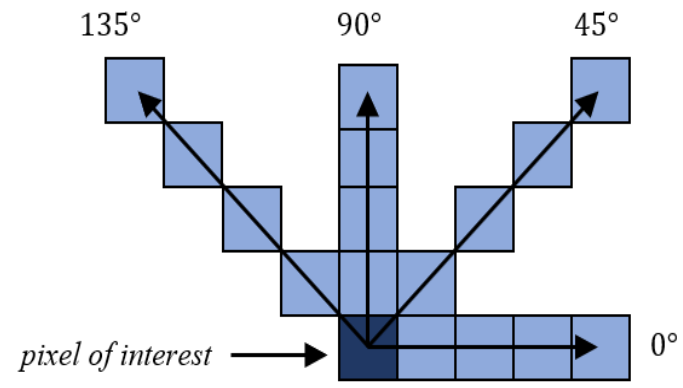

Gambar 4. Arah kejadian-bersama (co-occurrence) GLCM.

\subsection{Fusi Informasi}

Fusi Informasi adalah suatu metode yang digunakan untuk menggabungkan beberapa fitur menjadi satu fitur yang mewakili fitur-fitur yang ada. Penggabungan informasi ini dapat dari hasil pengujian bagaimana manusia dapat membuat sebuah keputusan yang akurat dari beberapa informasi yang sudah didapatkan. Selain itu, manusia juga dapat memperkirakan/memprediksi situasi yang akan terjadi di masa depan dengan menggabungkan informasi yang sudah didapatkan. Setelah informasi tersebut digabungkan informasi tersebut menjadi sebuah dasar dalam pengambilan keputusan. (Sumari \& Ahmad, 2016).

Fusi informasi pada dasarnya ekstraksi pengetahuan dari sekumpulan data (Sumari \& Ahmad, 2017). Terdapat beragam metode untuk fusi informasi dan juga tatarannya, terdiri atas mode DataFitur-Obyek-Relasi yang dipetakan dalam bentuk tabel yang bersesuaian (Sumari \& Ahmad, 2008). Dalam penelitian ini dipilih mode Feature In-Feature Out (FEI-FEO) yakni masukan berupa dua fitur berbeda dan keluaran berupa sebuah fitur terfusi sebagaimana diperlihatkan pada Persamaan (11). Fusi informasi secara digital dapat dilakukan menggunakan beragam operator biner seperti $A N D$ dan $X O R$. Pada konteks penelitian ini, fusi informasi akan dilakukan pada tingkat fitur yakni fusi fitur warna dan tekstur.

$$
\text { Fitur_terfusi }=\text { Fitur }(i) \oplus \text { Fitur }(i+1)
$$

Bila $\operatorname{Fitur}(i)=$ warna dan $\operatorname{Fitur}(i+1)=$ tekstur , maka:

$$
\text { Fitur_terfusi }=\text { Fitur }(\text { warna }) \oplus \text { Fitur }(\text { tekstur })
$$

dengan $\oplus$ adalah operator fusi informasi berupa operator digital sederhana seperti $A N D$ atau $X O R$.

Dalam penelitian ini fitur warna diperoleh dari metode HSV, sedangkan fitur tekstur diperoleh dari metode GLCM yang diambilkan dari salah satu komponennya yakni Energi. Salah satu penelitian membandingkan akurasi hasil klasifikasi menggunakan empat dan lima fitur dari GLCM (Irawan dkk, 2018) yang diperoleh hasil akurasi yang sama. Fusi fitur pada pengolahan citra digital juga digunakan oleh (Su \& Chen, 2013). Dalam penelitian ini, klasifikasi menggunakan dua fitur dari dua metode yang berbeda.

Pertimbangan menggunakan komponen Energi dari GLCM adalah komponen ini menggambarkan keteraturan penyebaran derajat keabuan satu citra (Lihayati, Pawening, \& Furqan, 2016) dan merefleksikan homogenitas distribusi skala keabuan dan kekasaran tekstur (Zhao, Shi, \& Luo, 2014). Keteraturan tekstur menunjukkan pengulangan pola tekstur secara teratur sehingga memudahkan dalam merepresentasikannya ke model matematika (Awaliyh, 2014).

\subsection{Support Vector Machine (SVM)}

SVM merupakan salah satu teknologi Kecerdasan Artifisial machine learning yang dibangun dari berdasarkan pembelajaran statistik. Konsep SVM dapat dijelaskan secara sederhana sebagai usaha mencari hyperplane terbaik yang berfungsi sebagai pemisah dua buah kelas pada ruang masukan (input space). Pola (pattern) yang merupakan anggota dari dua buah kelas: +1 dan -1 dan berbagi alternatif garis pemisah (discrimination boundaries). Margin adalah jarak antara hyperplane tersebut dengan pola terdekat dari masing-masing kelas. Pola yang memiliki jarak paling dekat disebut sebagai support vector. Usaha untuk mencari lokasi hyperplane merupakan inti dari proses pembelajaran pada SVM (Ririd, Kurniawati, \& Yunhasnawa, 2018).

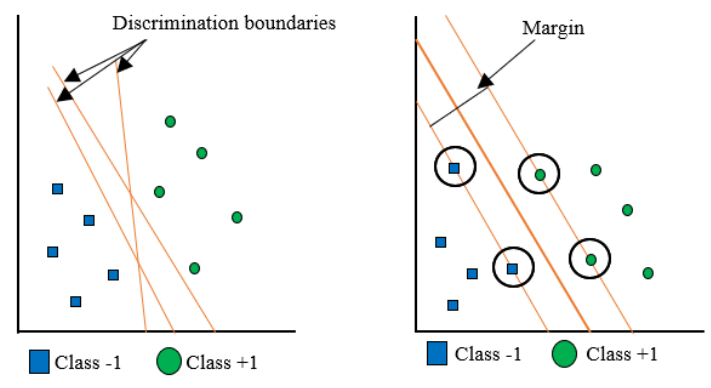

Gambar 5. Hyperplane yang memisahkan dua kelas.

Terdapat beberapa fungsi kernel yang digunakan untuk menyelesaikan masalah pada SVM yang salah satunya adalah fungsi kernel Radial Basis Function (RBF) dapat dilihat pada Persamaan (16) (Ririd, Kurniawati, \& Yunhasnawa, 2018). Langkahlangkah dalam melakukan pelatihan dan pengujian SVM dapat dilihat dalam (Kusuma, Pawening, \& Dijaya, 2017).

$$
k(x, y)=\exp \frac{\left(-\|x-y\|^{2}\right)}{2 \sigma^{2}}
$$




\section{IMPLEMENTASI DAN PENGUJIAN SISTEM PEMILIHAN DAGING KELAPA BERMUTU MENGGUNAKAN SVM DAN FUSI INFORMASI}

\subsection{Implementasi Sistem}

Sistem pemilihan daging kelapa bermutu menggunakan metode SVM dan fusi informasi diimplementasikan ke dalam bentuk aplikasi perangkat lunak menggunakan bahasa pemrograman C\#.

\subsection{Pengujian Sistem}

Kinerja sistem dalam melakukan klasifikasi daging kelapa sebagai cara untuk memilih kualitas yang bermutu diukur dari nilai akurasinya. Pengujian dilakukan dengan memberikan masukan kepada sistem sebanyak 20 citra daging kelapa yang belum pernah dipelajari yang terdiri atas 10 citra daging kelapa bermutu baik dan 10 citra daging kelapa bermutu kurang baik. Nilai akurasi diperoleh menggunakan Persamaan (17) (Han, Kamber, \& Pei, 2012). Hasil-hasil pengujian ditampilkan pada Tabel 1 dalam bentuk confusion matrix.

$$
\text { accuracy }=\frac{T P+T N}{\text { Total }} \times 100 \%
$$

\begin{tabular}{|c|c|c|}
\hline $\mathbf{n}=\mathbf{2 0}$ & \multicolumn{2}{|c|}{ Kelas Prediksi Hasil Klasifikasi } \\
\hline Kelas Sebenarnya & $\begin{array}{c}\text { Kelas } 1 \\
\text { (Mutu Baik) }\end{array}$ & $\begin{array}{c}\text { Kelas } 2 \\
\text { (Mutu Kurang } \\
\text { Baik) }\end{array}$ \\
\hline $\begin{array}{c}\text { Kelas } 1 \\
\text { (Mutu Baik) }\end{array}$ & $\mathrm{TP}=10$ & $\mathrm{FN}=10$ \\
\hline $\begin{array}{c}\text { Kelas } 2 \\
\text { (Mutu Kurang Baik) } \\
\end{array}$ & $\mathrm{FP}=0$ & $\mathrm{TN}=0$ \\
\hline $\begin{array}{l}\text { Total Hasil } \\
\text { Klasifikasi } \\
\end{array}$ & $10 \mathrm{TP}$ & $10 \mathrm{FN}$ \\
\hline
\end{tabular}

Berdasarkan pada data hasil pengujian di atas, diperoleh nilai akurasi sebesar $50 \%$.

accuracy $=\frac{10+0}{20} \times 100 \%=50 \%$

\section{ANALISA DAN PEMBAHASAN}

\subsection{Analisa}

Sistem pemilihan daging kelapa bermutu menggunakan SVM dan fusi informasi telah berhasil menjalankan mekanisme yang disampaikan pada Gambar 4 mengikuti diagram alir pada Gambar 5. Ekstraksi fitur warna menggunakan metode HSV, dan fitur tekstur menggunakan GLCM yang kemudian dilanjutkan dengan fusi terhadap kedua fitur diperlihatkan pada Gambar 6 hingga Gambar 8 . Pelatihan dan pengujian kinerja sistem diperlihatkan pada Gambar 9 dan Gambar 10.

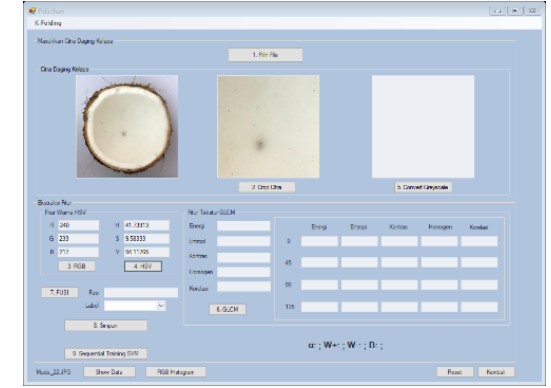

Gambar 6. Ekstraksi fitur warna dari RGB menjadi HSV.

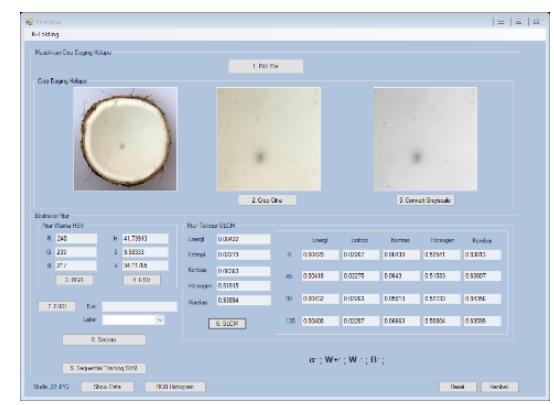

Gambar 7. Ekstraksi fitur tekstur menggunakan GLCM.

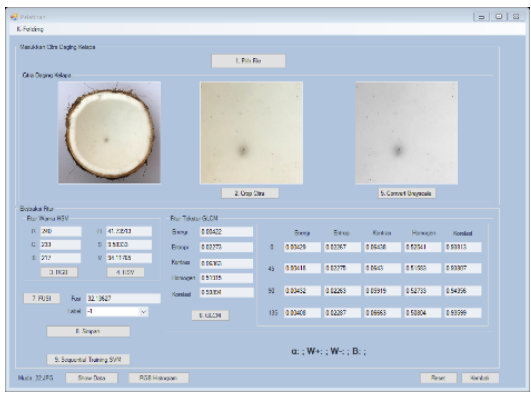

Gambar 8. Fusi fitur dan pelabelan fitur.

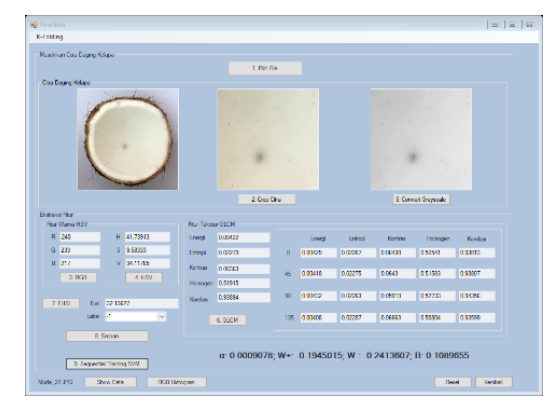

Gambar 9. Pelatihan sistem

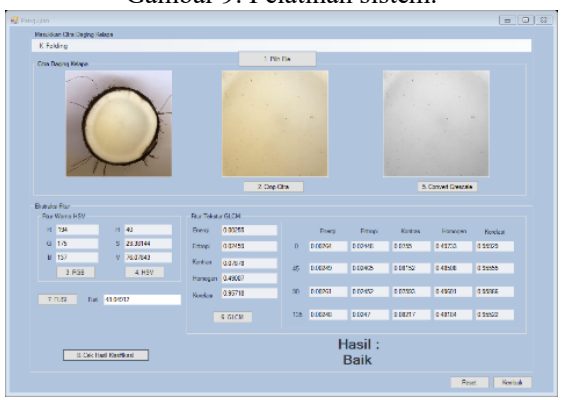

Gambar 10. Pengujian kinerja sistem

\subsection{Pembahasan}

Akurasi sistem sebesar $50 \%$ tidak selalu menyatakan bahwa SVM sebagai pengklasifikasi 
berkinerja buruk. SVM memiliki karakteristik pembelajaran disupervisi (supervised) yakni harus dilatih dulu dengan data yang dilengkapi dengan label dari data yang dilatihkan agar SVM memiliki pengetahuan tentang data tersebut. Pelabelan daging kelapa baik yang bermutu baik maupun yang bermutu kurang baik dilakukan langsung oleh para pekerja perusahaan wingko.

Berdasarkan hasil survei langsung ke lapangan, UD. Putra Agung hanya mengandalkan dua fitur dari daging kelapa yakni fitur warna dan fitur tekstur. Pelabelan kualitas daging kelapa dilakukan oleh para pegawai perusahaan tersebut secara subyektif berdasarkan organ-organ pengindraan mereka dan berisiko mempengaruhi akurasi sistem pengklasifikasi. Ketidaktepatan dalam pelabelan data akan berdampak pada hasil klasifikasi SVM sehingga dapat menghasilkan akurasi klasifikasi yang rendah sebagaimana diperlihatkan pada Tabel 2.

\begin{tabular}{|c|c|c|c|c|}
\hline No. & $\begin{array}{c}\text { Kategori } \\
\text { Kelapa }\end{array}$ & Label & $\begin{array}{c}\text { Nilai } \\
\text { Fitur } \\
\text { Fusi }\end{array}$ & $\begin{array}{c}\text { Label } \\
\text { Seharusnya }\end{array}$ \\
\hline \multicolumn{5}{|c|}{ Kelapa Bermutu Baik } \\
\hline 1. & Muda_52.JPG & 1 & 34.0169 & 1 \\
\hline 2. & Muda_46.JPG & 1 & 34.09672 & 1 \\
\hline$\ldots$ & $\ldots$ & $\ldots$ & $\ldots$ & $\ldots$ \\
\hline 90. & Muda_25.JPG & 1 & 34.68764 & 1 \\
\hline $\begin{array}{r}\text { Pers } \\
\text { L }\end{array}$ & $\begin{array}{l}\text { ase Kesalahan } \\
\text { el (Pekerja) }\end{array}$ & \multicolumn{3}{|c|}{$0 / 90=0 \%$} \\
\hline \multicolumn{5}{|c|}{ Kelapa Bermutu Kurang baik } \\
\hline 1. & Tua_84.JPG & -1 & \multirow{2}{*}{$\begin{array}{c}2.04255 \\
32.00013\end{array}$} & -1 \\
\hline 2. & Tua_37.JPG & -1 & & 1 \\
\hline$\cdots$ & & $\cdots$ & & $\ldots$ \\
\hline 90. & Tua_50.JPG & -1 & 32.00244 & 1 \\
\hline \multicolumn{2}{|c|}{$\begin{array}{c}\text { Persentase Kesalahan } \\
\text { Label (Pekerja) }\end{array}$} & \multicolumn{3}{|c|}{$45 / 90=50 \%$} \\
\hline
\end{tabular}

Berdasarkan dari nilai akurasi tersebut, dilakukan pelacakan ke belakang dengan membandingkan hasil ekstraksi fitur dengan pelabelan dari pekerja. Dari hasil pelacakan diperoleh hasil bahwa terjadi perbedaan penilaian dari sistem dan manusia khususnya pada daging kelapa yang bermutu kurang baik.

Temuan memperlihatkan bahwa pekerja kemungkinan besar melakukan tidak tepatan dalam menilai kelapa yang bermutu kurang baik karena 50\% pelabelan yang diberikan bertolak belakang dengan hasil penilaian sistem. Untuk kelapa yang bermutu baik, pelabelan oleh pekerja identik dengan hasil penilaian oleh sistem sehingga hasil klasifikasi SVM menghasilkan akurasi $100 \%$. (FP $=10$ dari 10 data uji). Ketidaktepatan pelabelan sama halnya dengan memberikan data yang salah kepada sistem.

Dalam penelitian ini juga diperlihatkan bahwa fusi informasi memberikan kontribusi dalam mempercepat proses klasifikasi oleh SVM. Tanpa fusi informasi, maka proses klasifikasi akan memakan waktu dua kali lebih lama yang mana klasifikasi akan dilakukan secara fitur per fitur.

\section{KESIMPULAN DAN TINDAK LANJUT}

\subsection{Kesimpulan}

Kombinasi SVM dan fusi informasi dapat dimanfaatkan dalam pemilihan bahan dasar wingko yang bermutu berdasarkan pada warna dan tekstur daging buah kelapa. Sistem berhasil $100 \%$ memprediksi daging kelapa bermutu baik namun gagal memprediksi yang sebaliknya, sehingga secara keseluruhan akurasi prediksi sistem adalah 50\%. Kegagalan prediksi bukan semata karena kinerja sistem yang buruk namun sangat dipengaruhi oleh label data yang diberikan oleh manusia.

Dari akurasi tersebut juga dapat disimpulkan bahwa kinerja sistem sangat dipengaruhi oleh subyektivitas manusia dalam memberikan penilaian yang digunakan untuk melabeli data-data latih dan uji. Bila data buruk atau salah maka metode SVM tidak akan ada gunanya (Redman, 2018) atau sistem akan memberikan jawaban yang salah (MacLaughlin, 2018). Faktor manusia berperan sangat penting dalam menentukan akurasi dari sistem klasifikasi.

\subsection{Tindak Lanjut}

Ada beberapa hal yang dapat dilakukan yakni memperbaiki pelabelan data dan membangun metode fusi informasi alternatif guna memperoleh fitur terfusi yang lebih baik. Untuk ekstraksi fitur, dapat menggunakan metode-metode lain guna memperoleh fitur yang lebih representatif.

\section{DAFTAR PUSTAKA}

AWALIYAH, 2014. Rancang Bangun Sistem Temu Kembali Gambar Ikan Berdasarkan Ekstraksi Ciri Warna, Bentuk dan Tekstur, Universitas Islam Negeri Sultan Syarif Kasim Riau [online]. Tersedia di: < http://repository.uin-suska.ac.id/3537/> [Diakses 16 Juni 2020].

KUSUMA, S.F., PAWENING, R.E., \& DIJAYA, R., 2017. Otomasi Klasifikasi Kematangan Buah Mengkudu berdasarkan Warna dan Tekstur, Jurnal Ilmiah Teknologi Sistem Informasi, 3(1), pp. 19-22, [online]. Tersedia di: < https://www.journal.unipdu.ac.id/index.php /register/article/view/576> [Diakses $10 \mathrm{Mei}$ 2020].

NURUL L., PAWENING R.E., \& FURQAN, M. 2016. Klasifikasi Jenis Daging Berdasarkan Tekstur Menggunakan Metode Gray Level Cooccurrent Matrix. Prosiding SENTIA 2016, 8 [online]. Tersedia di: < http://sentia.polinema.ac.id/index.php/SEN TIA2016/article/view/59> [Diakses 6 Mei 2020].

MACLAUGHLIN, S., Bad AI Comes from Bad Data [online]. Tersedia di: $<$ https://www.huffpost.com/entry/bad-aicomes-from-bad- 
data_b_5a4a760ee4b0df0de8b06c0f>

[Diakses 21 Juli 2020].

PULUNG, A.N., SUTOJO, T., \& MULJONO., 2017. Pengolahan Citra Digital. Edisi 1. Yogyakarta: Penerbit Andi.

PUTRA, D., 2010. Pengolahan Citra Digital. Edisi 1. Yogyakarta: CV Andi Offset.

REDMAN, T.C., 2018. If Your Data Is Bad, Your Machine Learning Tools Are Useless [online]. Tersedia di: $<$ https://hbr.org/2018/04/if-your-data-isbad-your-machine-learning-tools-areuseless $>$ [Diakses 25 Juli 2020].

RIRID, A.T.H., KURNIAWATI, A.W., \& YUNHASNAWA, Y., 2018. Implementasi Metode Support Vector Machine untuk Identifikasi Penyakit Daun Tanaman Kubis, Jurnal Informatika Polinema, 4(3), pp. 18287.

SAIFUDIN, \& FADLIL, A., 2015. Sistem Identifikasi Citra Kayu Berdasarkan Tekstur Menggunakan Gray Level Coocurrence Matrix (GLCM) Dengan Klasifikasi Jarak Euclidean. SINERGI, 19(3), pp. 181-186 [online]. Tersedia di: < https://sinergi.mercubuana.ac.id/media/165 465-sistem-identifikasi-citra-kayuberdasark-8ca84979.pdf $>$ [Diakses 4 April 2020].

SETYAMIDIJAYA, D., 2008. Bertanam Kelapa. Cetakan 9, Yogyakarta: Penerbit Kasinius.

SIDDESHA, S., \& NIRANJAN, S.K., 2019. Color and Texture in Classification of Coconut. International Journal of Innovative Technology and Exploring Engineering (IJITEE), 8(8), pp. 1745-1750.

SU, S.Z., \& CHEN, S.Y., 2013. Analysis of feature fusion based on HIK SVM and its application for pedestrian detection, [online]. Tersedia di: < https://www.hindawi.com/journals/aaa/201 3/436062/> [Diakses 4 April 2020].

SUKRAMA, U., 2009. Aneka Ragam Khas Jawa Timur. Bandung:PT Sarana Panca Karya Nusa.

SUMARI, A.D.W., \& AHMAD, A.S., 2008. Designing MultiAgent-based Information Fusion System. The $1^{\text {st }}$ Makassar International Conference on Electrical Engineering and Informatics 2008, pp. 137143.

SUMARI, A.D.W., \& AHMAD, A.S., 2016. The Fusion of Artificial Intelligence and Information Fusion. International Symposium on Electronics and Smart Devices 2016, [online]. Tersedia di: < https://ieeexplore.ieee.org/document/78867 54> [Diakses 21 Mei 2020].
SUMARI, A.D.W., \& AHMAD, A.S., 2017. Information Fusion as Knowledge Extraction in an Information Processing System. International Journal of Artificial Intelligence and Neural Networks, 7(1), pp. 22-27.

SURYA, R.A., FADLIL, A., \& YUDHANA, A., 2017. Ekstraksi Ciri Metode Gray Level CoOccurrence Matrix (GLCM) dan Filter Gabor Untuk Klasifikasi Citra Batik Pekalongan. Jurnal Informatika: Jurnal Pengembangan IT (JPIT), 2(2), pp. 23-26.

WAHYUDI, J. \& MAULIDA, I., 2019. Pengenalan Pola Citra Kain Tradisional Menggunakan GLCM dan KNN. JTIULM, 4(2), pp. 43-48 [online]. Tersedia di: < https://jtiulm.ti.ft.ulm.ac.id/index.php/jtiul $\mathrm{m} /$ article/view/37> [Diakses 17 Maret 2020].

WARISNO, 2003. Budi Daya Kelapa Genjah. Cetakan ke-1. Yogyakarta: Penerbit Kanisius.

WIDYARDINI, S.T., 2015. Pemrograman Matlab untuk Pengolahan Citra Digital Studi Kasus Sistem Pemantau Ruangan Pengganti CCTV. Cetakan Pertama, Malang: UB Press.

WIRYADINATA, R., ADLI, M. R., FAHRIZAL, \& R., ALFANZ, R., 2019. Klasifikasi 12 Motif Batik Banten Menggunakan Support Vector Machine. Jurnal EECCIS, 13(1), pp. 60-64 [online]. Tersedia di: < https://jurnaleeccis.ub.ac.id/index.php/eecci s/article/view/570> [Diakses 20 Juni 2020].

ZHAO, Q., SHI, C., \& LUO, L., 2014. Role of the texture features of images in the diagnosis of solitary pulmonary nodules in different sizes. Chin J Cancer Res, 26(4), pp. 451-458 [online]. Tersedia di: < https://www.ncbi.nlm.nih.gov/pmc/articles/ PMC4153941/> [Diakses 18 Juli 2020]. 